\title{
Enroute to Managed Learning Environment: A Case Study of Lyallpur Khalsa College, Jalandhar, India
}

\author{
Baldev Singh, \\ Lyallpur Khalsa College, Jalandhar, India
}

bsd@india.com

\begin{abstract}
Managed Learning Environment (MLE) uses technology to enhance and make more effective the network of relationships between learners, teachers and organizers of learning, through integrated support for richer communications and activities". Educational institutions are faced with the challenge of setting up of a hi-tech infrastructure and preparing a new generation of teachers to effectively use the new learning technology based tools in their teaching practices. For managed learning teacher education programmes, managed learning environment requires the acquisition of new resources, expertise and careful planning. The Managed Learning Environment enables any student or teacher to collaborate with educators, evaluate academic performance and access learning resources at any time to achieve their educational objectives. This paper also highlights the adequate implementation of MLE at Lyallpur Khalsa College.
\end{abstract}

Keywords: Managed Learning Environment, knowledge, education, resources, planning and technology

\section{Introduction}

In the modern world, educational systems are under escalating heaviness to use the new information and communication technologies (ICTs) to teach students the knowledge and skills they need in the 21st century. The 1998 UNESCO World Education Report, Teachers and Teaching in a Changing World, describes the radical implications the new information and communication technologies have for conventional teaching and learning. It states: (a) To effectively harness the power of the new information and communication technologies (ICTs) to improve learning, the following essential conditions must be met. (b) Students and teachers must have sufficient access to digital technologies and the Internet in their classrooms, schools, and teacher education institutions. (c) High quality, meaningful, and culturally responsive digital content must be available for teachers and learners. (d) Teachers must have the knowledge and skills to use the new digital

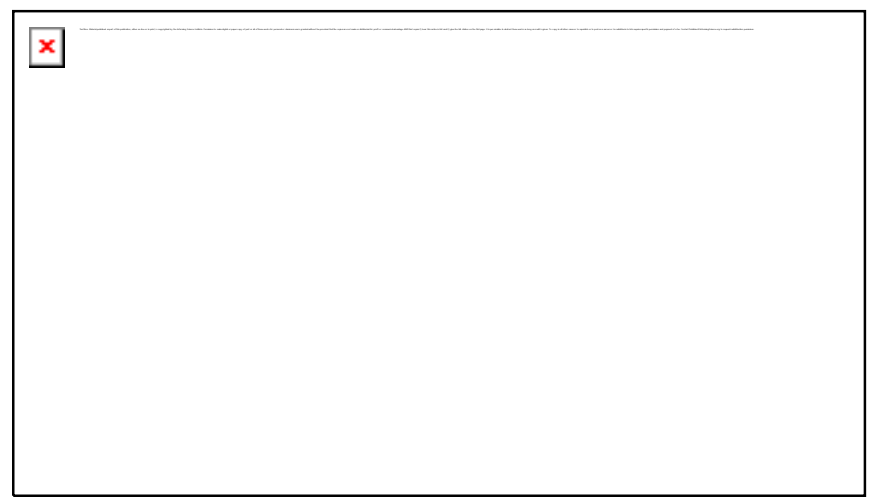
tools and resources to help all students achieve high academic standards.

A Managed Learning Environment is a system that uses technology to enhance and make more effective the network of relationships between learners, teachers and organizers of learning, through integrated support for richer communication and activities. Managed Learning Environments have the need of new generation teachers that are well versed 
with new learning tools. Teacher education institutions are faced with the challenge of preparing a new generation of teachers to effectively use the new learning tools in their teaching practices. For many teacher education programmes, this daunting task requires the acquisition of new resources, expertise and careful planning. For education to reap the full benefits of MLE in learning, it is essential that pre-service and in-service teachers have basic ICT skills and competencies. Education is at the convergence of powerful and rapidly shifting educational, technological and political forces that will shape the structure of educational systems across the globe for the remainder of this century. India like other developing countries, is in process to put a number of efforts to effect changes in the teaching/ learning process to prepare students for an information and technology based society. The result is clear that, Punjab (some other states also) state deployed computers in its all-high and senior secondary schools this year. A paradigm shift in views of the learning process, coupled with applications of the new information technologies, may play an important role in bringing educational systems into alignment with the knowledge-based society.

\section{The Conventional Structure of the Learning Process}

The existing view of the learning process emerged out of the factory model of education at the turn of the 20th century and was highly effective in preparing large numbers of individuals with skills needed for low-skilled positions in industry and agriculture. The innovation of classrooms with 20- 30 students was created along with the concept of standardized instruction for everyone. It is largely a 'broadcast' model of learning where the teacher serves as the repository and transmitter of knowledge to the students. The dominance of this view is supported by observations that teachers continue to rely on old standbys such as lectures, textbook reading, and fill-in-theworksheets practices that reduce students to passive recipients of information and fail to develop their thinking skills. The conventional view of teaching is based on the following process of Learning:

Learning is an individual/solitary process. In a study of schools in the United States, the National Assessment of Educational Progress noted that most students spend long hours working alone at their desks completing worksheets or repetitive tasks. The new learning environment abandoned this daily torment of dull and ritualistically solitary classroom activity and called for a broader and more exciting curriculum.

Learning is a linear process. Frequently, the textbook or teacher provides only one linear path through a narrowly bounded content area or sequence of standardized instructional units. For example, in a mathematics text only one correct problem solution trail may be offered for a specific subclass of problems.

\section{Changes in Views of the Learning Process}

In contrast to the conventional teaching-learning paradigm, a new paradigm of the teachinglearning process is emerging, based on research in human learning, that encompasses the following views of the human learning process:

Learning is a natural process. The natural state of the brain is to learn, however, not everyone learns in the same way. There are different learning, perceptual and personality styles that must be considered in the design of learning experiences for the individual student. Given interesting and rich learning environments, and supportive and stimulating teachers, students will learn. Teachers have often noted that children who appear disruptive or to have short attention spans when confronted with typical classroom instruction, may spend long periods engaged in meaningful and interesting computer- related activities. 
Learning is a social process: ICTs provide opportunities for teachers and students to collaborate with others across the country and across the globe. They also provide new tools to support this collaborative learning in the classroom and online. As Vygotsky (1978) noted long ago, students learn best in collaboration with peers, teachers, parents, and others when they are actively engaged in meaningful, interesting tasks.

Learning is an active process. In most fields, people are faced with the challenge of producing knowledge rather than simply reproducing knowledge. To allow students to move toward competence, they must be actively engaged in the learning process, in activities such as solving real problems, producing original writing, completing scientific research projects (rather than simply studying about science), dialoguing with others on important issues, providing artistic and musical performances, and constructing physical objects.

Learning is based on a strength model of student abilities, interest, and culture. Based on the work of Howard Gardner and others, schools are beginning to consider the specific strengths and interests that students bring to the learning environment, and are designing learning activities that build on student strengths rather than focusing only upon remediating weaknesses.

\section{A Shift from Teaching to Learning}

With the advancements in technology, changes are made in all aspects of society; it is also changing our expectations of what students must learn in order to function in the new world economy. Students will have to learn to navigate through large amounts of information, to analyze and

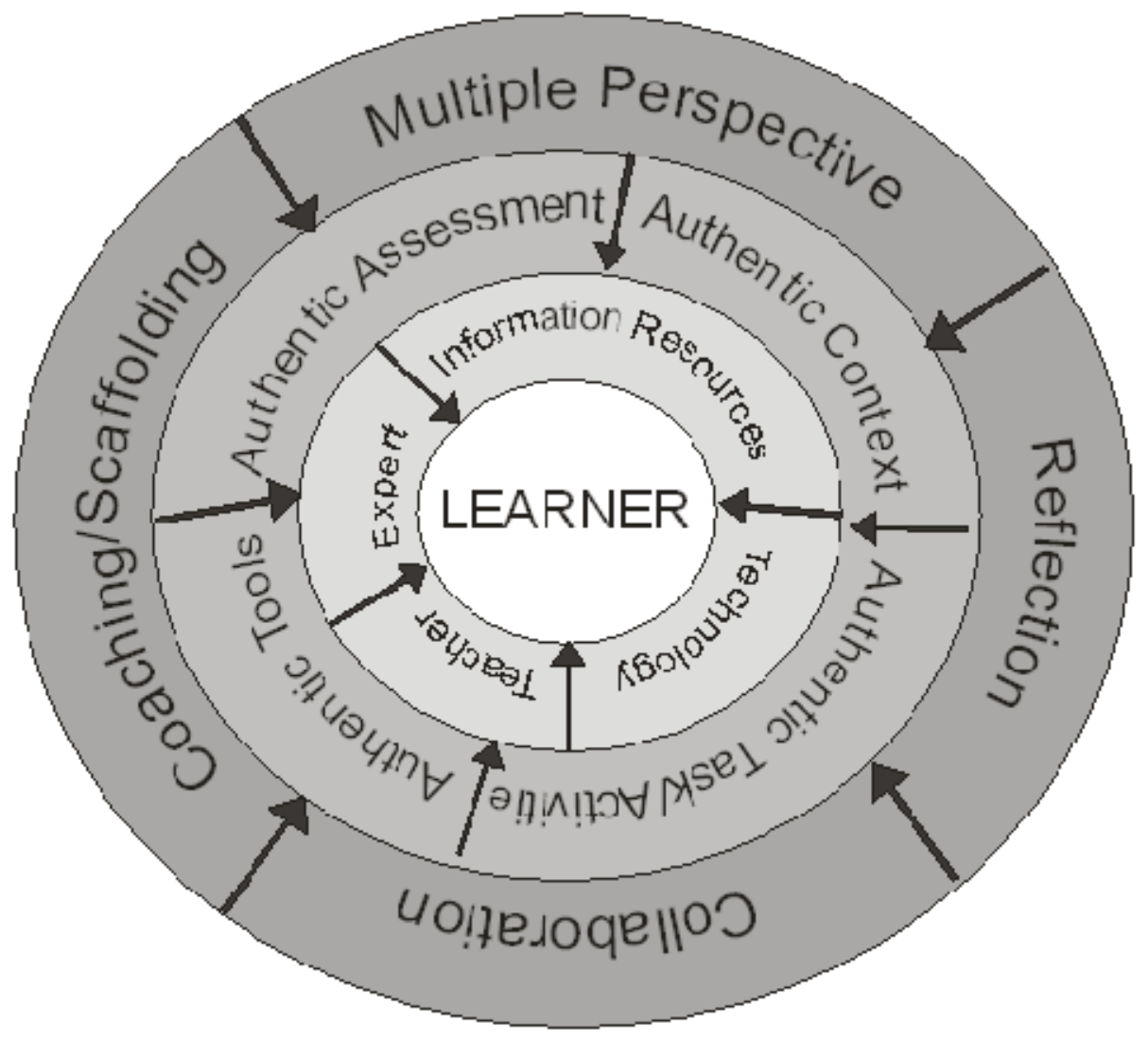

Figure 1: Stident-Cenered Learning Invironment 
make decisions, and to master new knowledge domains in an increasingly technological society. The Managed Learning Environment provides the student-centered environment for learning. The following figure shows student-centered environment.

The Figure 1 shows that the learner interacts with other students, the teacher, information resources, and technology. The learner engages in authentic tasks in authentic contexts using authentic tools and is assessed through authentic performance. The environment provides the learner with coaching and scaffolding in developing knowledge and skills. It provides a rich collaborative environment enabling the learner to consider diverse and multiple perspectives to address issues and solve problems. It also provides opportunities for the student to reflect on his or her learning. Although the new learning environment can be created without the use of technology, it is clear that ICTs can provide powerful tools to help learners access vast knowledge resources, collaborate with others, consult with experts, share knowledge, and solve complex problems using cognitive tools. ICTs also provide learners with powerful new tools to represent their knowledge with text, images, graphics, and video. This environment states that learning is much more than classes and grades. It is about the learning that takes place in a vibrant community of

\section{Media and Technology Used in Learning Environment}

Media and technology plays a vital role in learning. Various objects of media and technology are: Print, Television, Radio, Audio/video, cassettes, videoconferencing, and production of computerbased teaching material, computer, and conferencing. These can be relatively low cost, depending on development costs and scale of use and can be used in different ways for learning (under the control of the learner who can stop, start and re-play sequences). Media and technology can support active learning with good instructional design, demonstrate teachers' beliefs and practices, stimulate discussion, show the realities of teaching and defend to provides opportunities for practice and experiment followed by feedback; helps the student-teacher develop specific skills (such as questioning, explaining, managing time-on-task, setting up group-work, using a particular teaching method). Video-conferencing enables real-time interaction among teachers and educators in different locations. It can bring together teachers, curriculum developers, specialists and policy makers in one event can be used for presentations and teaching sessions, discussions, course delivery (in combination with other media) and student support.

\section{Virtual Learning Environment}

A Managed learning environment is a half way, if is promoted without Virtual Learning Environment (VLE).The components of a VLE include the following:

- notice-board/bulletin board

- course outline (course structure, assignments, assessment dates)

- email facility

- conferencing tools (asynchronous conferencing or discussion groups)

- $\quad$ student home pages

- metadata (ability to add metadata to resources)

- assignments (ability for tutor to create assignments)

- assessments

- $\quad$ synchronous collaboration tools (such as whiteboards, chat and video conferencing)

- multimedia resources (accessing, storing and creation)

- file upload area (ability for students to upload their resources to a shared area) 
MLE stresses the network of relationships within a managed learning environment. The development of the virtual learning environment is intrinsically a collaborative venture with quality processes, business systems, learning resources and other colleges/ agencies. The Figure 2 (source: www.sconul.ac.uk/event_conf/egm2000/MLEpaper.doc ) depicts the whole process of MLEs.

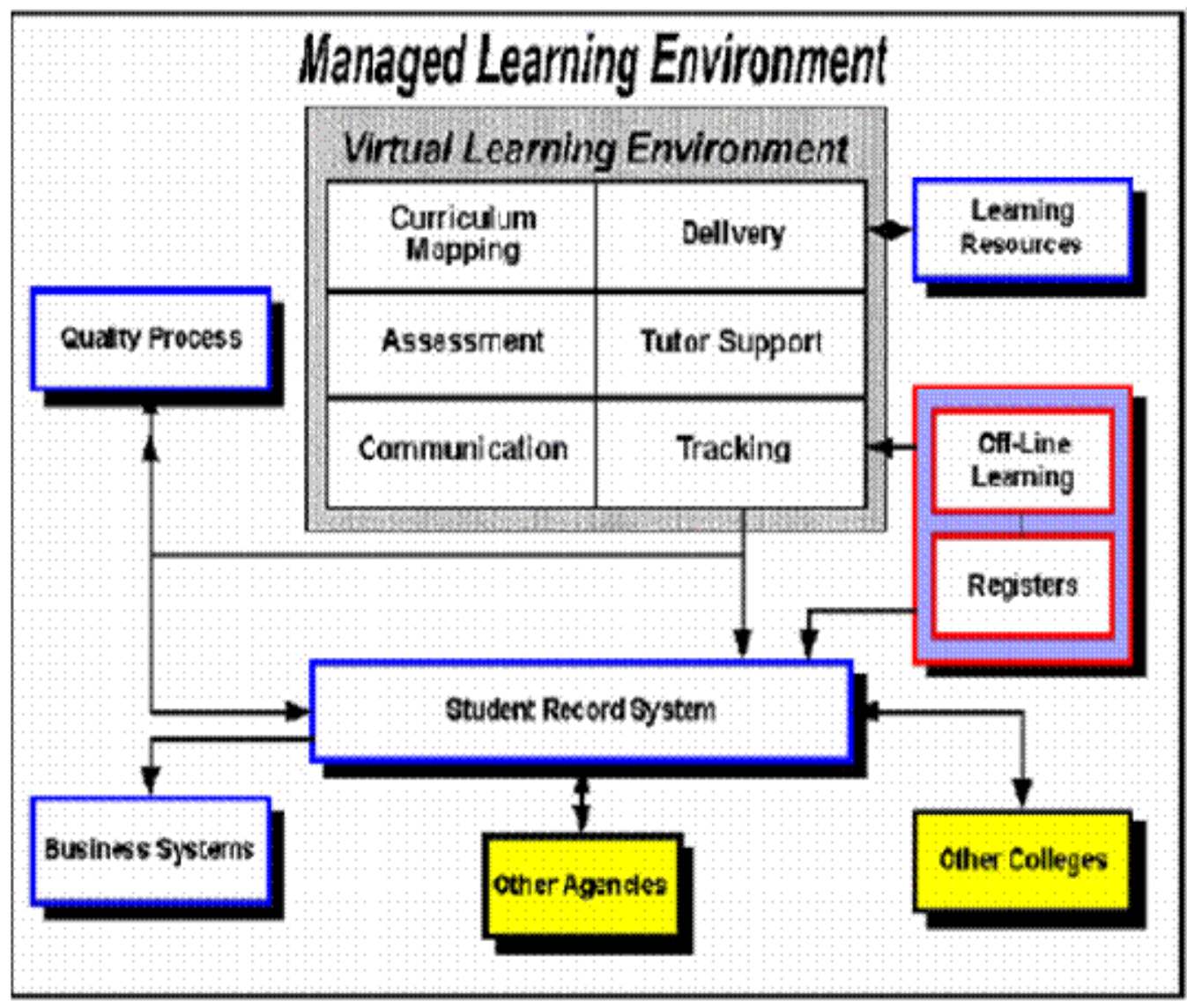

Figure 2: Schematic of a VLE as a sub-system

Novelty of the VLE is proved from the following facts as it meets needs of the learning:

- Accessibility. Knowledge can be access at anytime and anywhere.

- Flexibility. The e-learning environment can be customized to an organization's needs.

- Extensibility. The system must allow for additional components to be integrated easily.

- Reusability. Content can be reused by creators or consumers

- Interoperability. The system should allow content and other data to be exchanged and shared by separate tools and.

- Scalability. The system should permit access to potentially hundreds of thousands of users and large content repositories.

- Security. The security of data, information, or knowledge should be promised in the system. 


\section{Creating the Learning Community}

The MLE goes on to propose a set of characteristics for modern infrastructure with the aim to create the learning community. When implemented, an MLE simultaneously increase access (via the network), improve quality (through the availability of individualized, interactive learning materials) and contain costs (by reducing labor intensity in instruction).To achieve these goals, we must create an advanced technological infrastructure and we must stimulate the Managed Learning Environment that enables any student or teacher to collaborate with educators, evaluate academic performance and access learning resources at any time to achieve their educational objectives.

\section{MLE At Lyallpur Khalsa College (LKC), Jalandhar}

Technology is a catalyst for significant changes in learning practice. Students and teachers adopt new roles and relationships. Technology feeds into interactive learning which in turn feeds into learner-directed learning which is also affected by the change in roles of students and teachers. A wide range of learning technologies are selected and incorporated into the teaching and learning program. Most staff regularly use a range of learning technologies and are integrating these into the teaching and learning program. Provision of learning activities is adequate to facilitate daily use by all students in most learning areas. There is a planned approach to future hardware requirements. The conventional lecture method of teaching in the College is supplemented by other learner - centered teaching methods, such as slides, charts, online information, OHP and LCD projectors, exhibitions, seminars, guest lectures, extempore, debates and quiz etc. The college has introduced innovative approaches in the instructional technology to strengthen the conventional methods of teaching. There is facility of preparing audio visual and other teaching aids. This has produced significant results by bagging several top positions in University Examinations every year. That is why NAAC (National Assessment and Accreditation Council, An autonomous Institution of the University Grants Commission, India) rated $\mathbf{A}^{+}$status to Lyallpur Khalsa College (source: http://www.naac-india.com/colleges.asp?state=20). The following figures highlight the adequate adoption of MLE at LKC.

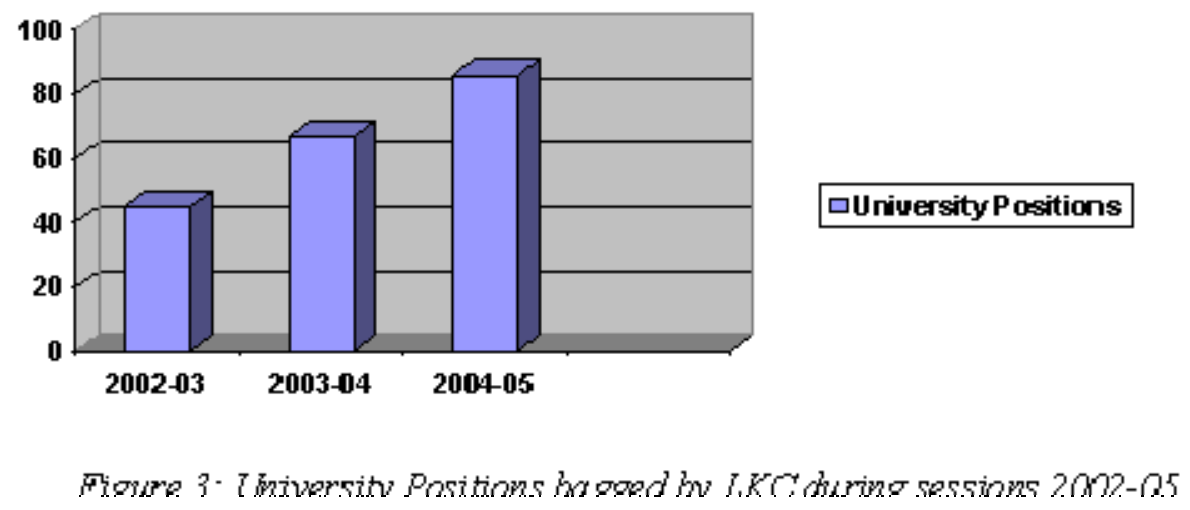

Figure 3 shows the increasing trends in quality of education. The number of top positions is increased. Figure 4 shows the increase in students' strength. The adequate facilities, which allow for varied modes of usage to maximize improvement in student learning and effective policies and procedures for the management of resources, are evidence of MLE at LKC. 


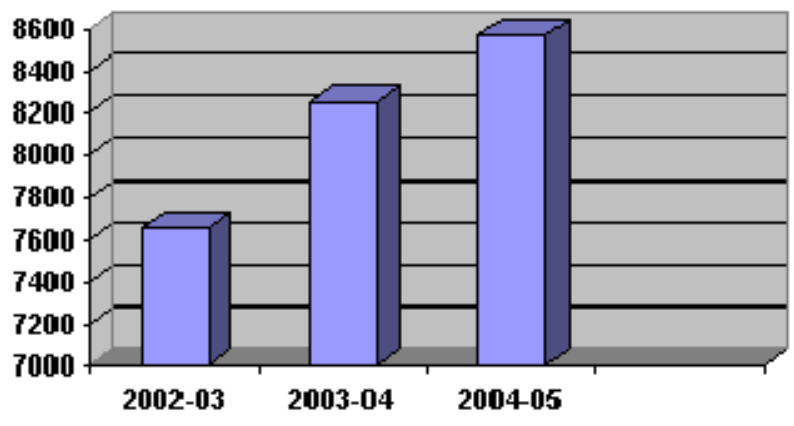

Figure 4: Students'streneth in LKC during sessions 2002-05

\section{Conclusion}

In this paper I have laid out my study where institutions should go for managed learning environment. It is because a very few institutions in developing countries like India have reached this stage today that the transition to Managed Learning Environment has become such a central direction for Learning. I have concluded surely, with the capabilities of the media and technology always changing and the imagination of educators, the idea and shape of a true Managed Learning Environment will continue to evolve at a rapid pace. But just as there is no such thing as achieving "full" education or "full" knowledge, it serves us best as a goal on the continuum. I have found that all the institutions of world especially in developing countries have been necessitated by the convergence of media and technology.

\section{References}

Backhouse, J., Land, F, \& Liebenau, J. (1991). On the discipline of information systems: Conflict in the trenches. Journal of Information Systems, 1, 19-27.

Barg, M., Fekete, A., Greening, T., Hollands, O., Kay, J., Kingston, J. H., et al. (2000). Problem-based learning for foundation computer science courses. Computer Science Education, 10 (2), 109-128.

Burgess, P. S. (1995). A guide for writing research papers. Retrieved June 3, 2001, from http://webster.commnet.edu/apa/apa_index.htm

Jesshope, C. \& Zhang, Z. (n.d.). A content management system for the TILE managed learning environment.

Lloyd, C. \& Watts, M. (2000). A classroom evaluation of Espresso for schools. Faculty of Education, University of Surrey, Roehampton.

Lynch, C. \& McLean, N. (2003). Interoperability between information and learning environments - Bridging the gaps : A Joint White Paper on behalf of the IMS Global Learning Consortium and the Coalition for Networked Information DRAFT - Version of June 28, 2003

Managed Learning Environment. (2003). The definition of MLEs provided by JISC stresses the network of relationships within a managed learning environment. Retrieved October 16, 2003. www.sconul.ac.uk/event_conf/egm2000/MLEpaper.doc

NAAC - National Assessment and Accreditation Council. (2006). Retrieved January 20, 2006 from http://www.naac-india.com/colleges.asp?state $=20$

Pittinsky, M. (n.d.). White paper on "The networked learning environment” Stepping beyond courses to a more expansive online learning experience. 
Rankine, L. (2001). The way ahead: Blackboard Or WebCT? A discussion paper. University of Western Sydney. Retrieved July 5, 2004 from http://www.webct.com/service/ViewContent?contentID=5720495

A review of the research literature on the use of managed learning. (n. d.). Retrieved September 20, 2005, from www.becta.org.uk/page documents/research/VLE_report.pdf

Vuorikari, R. (2003). Virutal learning in European schools. European Schoolnet. Retrieved January 18, 2004 from http://www.eun.org/eun.org2/eun/en/_News_search_news/content.cfm?lang=en\&ov=22814

Whitelock, D., \& Wilson, T. (1997). Monitoring a CMC environment created for distance learning. Journal of Computer Assisted Learning, 13, 253-260.

\section{Bibliography}

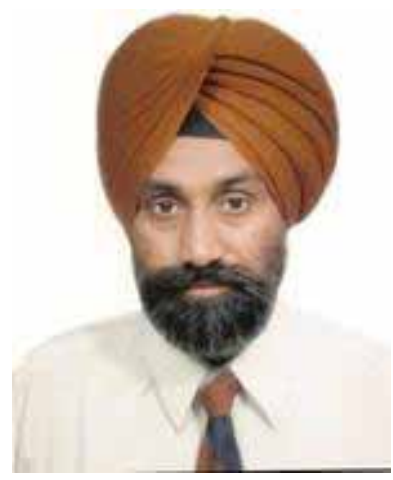

Baldev Singh, MCA, is currently employed as Lecturer in the Department of Computer Science \& IT, Lyallpur Khalsa College, Jalandhar, Punjab, India. He has contributed more than dozen papers at National and International Level Conferences catering to various important aspects of ICT. He is the co-author of four books covering areas of DBMS and Operating System. He is the Member of Faculty of Engineering \& Technology, Guru Nanak Dev University, Amritsar, Punjab, India and Institutional Member of Computer Society of India. 